\section{Synthesis and Crystal Structure of the First Tetraaminophosphonium Salt $\mathbf{P}\left(\mathbf{N H}_{2}\right)_{\mathbf{4}} \mathbf{I}^{* *}$}

Wolfgang Schnick, ${ }^{*}$ Stefan Horstmann, and Alfred Schmidpeter

\author{
Dedicated to Professor Otto J. Scherer \\ on the occasion of his 60th birthday
}

The characteristic building blocks in phosphorus(v) nitrides are $\mathrm{PN}_{4}$ tetrahedra. Linkage of these structural elements through common corners allows access to a large number of condensation degrees. This is reminiscent of the varied structural chemistry of the silicates and phosphates. ${ }^{[1]}$ One of the extremes in the series of differently condensed phosphorus nitrides is the ionic compound $\mathrm{Li}_{7} \mathrm{PN}_{4}$, which comprises "isolated" $\mathrm{PN}_{4}^{7-}$ ions. ${ }^{[2]}$ Due to its extremely high formal charge, no indications for the existence of this anion in solution have yet been found; therefore, $\mathrm{Li}_{7} \mathrm{PN}_{4}$ is accessible only by solid-state reaction of the corresponding binary nitrides. Thus, the certainly high synthetic potential of isolated $\mathrm{PN}_{4}$ groups in solution for the formation of well-defined $\mathrm{P}-\mathrm{N}$ solid compounds has remained unexplored.

The salt $\mathrm{Li}_{7} \mathrm{PN}_{4}$ is derived from the hypothetical acid $\mathrm{H}_{7} \mathrm{PN}_{4}$, which is suspected to be an unstable monophosphazene intermediate during ammonolysis of $\mathrm{PCl}_{5} \cdot{ }^{[3]}$ However, due to its high basicity and tendency to undergo condensation reactions it has not yet proven possible to isolate imidophosphoric acid triamide, $\mathrm{H}_{7} \mathrm{PN}_{4}$. With $\mathrm{P}\left(\mathrm{NH}_{2}\right)_{4} \mathrm{I}(\mathbf{C})$ we report the first successful synthesis and structural proof of a tetraaminophosphonium salt, which can be regarded as a hydroiodide of $\mathrm{H}_{7} \mathrm{PN}_{4}$. The synthesis followed the modification of a procedure ${ }^{[4]}$ that starts from phosphorothionic triamide (A).$^{[5]}$ Methylation of the sulphur atom in A with methyl iodide and careful subsequent ammonolysis of $\mathbf{B}$ readily yields the desired product $\mathbf{C}$. As the last

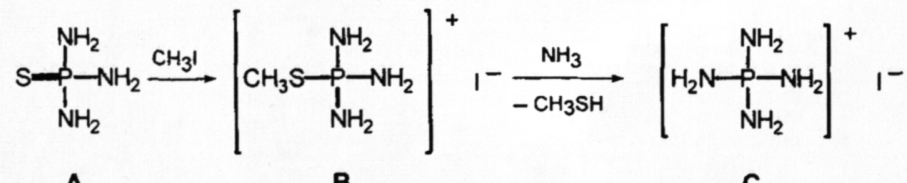

A

B

C

reaction step is a heterogeneous solid-liquid reaction, $\mathbf{C}$ is obtained as a sparingly-soluble, fine-crystalline powder. The crystal growth of tetraaminophosphonium iodide was severely hampered by the fact that $\mathbf{C}$ is insoluble in most solvents and that, due to its reactivity, it easily undergoes hydrolysis and condensation reactions. In the past methanol had been suggested as a solvent for $\mathbf{C}$. However, according to our investigations prolonged exposure of $\mathbf{C}$ to methanol leads to the formation of tetramethylammonium iodide [Eq. (a)]. Sufficiently large single crystals of $\mathbf{C}$ were obtained by crystallization from dry acetonitrile employing a temperature gradient between $70^{\circ} \mathrm{C}$ and room temperature. Obviously, tetraaminophosphonium iodide is sufficiently soluble at the higher temperature.

$4 \mathrm{P}\left(\mathrm{NH}_{2}\right)_{4} \mathrm{I}+4 \mathrm{CH}_{3} \mathrm{OH} \longrightarrow\left(\mathrm{CH}_{3}\right)_{4} \mathrm{NI}+4 \mathrm{OP}\left(\mathrm{NH}_{2}\right)_{3}+3 \mathrm{NH}_{4} \mathrm{I}$

[*] Prof. Dr. W. Schnick, Dipl.-Chem. S. Horstmann

Laboratorium für Anorganische Chemie der Universität

D-95440 Bayreuth (FRG)

Telefax: Int. code + (921)55-2531

Prof. Dr. A. Schmidpeter

Institut für Anorganische Chemie der Universität München (FRG)

$\left[{ }^{* *}\right]$ This work was supported by the Deutsche Forschungsgemeinschaft and the Fonds der Chemischen Industrie. We thank Dr. W. Milius, Universität Bayreuth, for help with and discussion of the X-ray structure analysis.
Unprecedented in chemistry, the acid-base pair $\mathrm{H}_{8} \mathrm{PN}_{4}{ }^{+}$/ $\mathrm{PN}_{4}^{7-}$ enables structural comparison over a range of eight successive dissociation steps: According to the results of the X-ray structure analysis, ${ }^{[6]} \mathrm{P}\left(\mathrm{NH}_{2}\right)_{4}^{+}$and $\mathrm{I}^{-}$ions form a CsCl-analogous arrangement in the solid. The $\mathrm{P}-\mathrm{N}$ bond length $(160.7(2) \mathrm{pm})$ (Fig. 1) represents the shortest $\mathrm{P}-\mathrm{NH}_{2}$ bond distance reported to date. The valence sum for the phosphorus center (5.56), calculat-

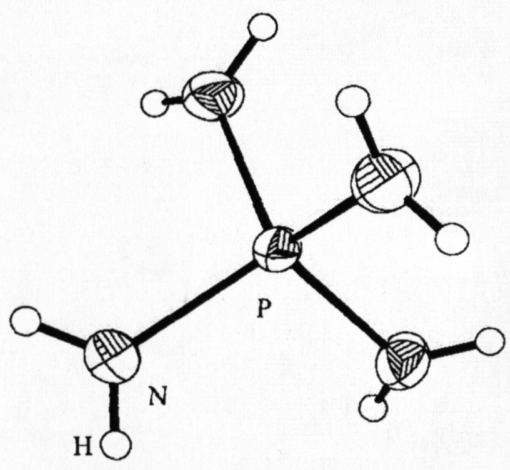

Fig. 1. Structure of the tetraaminophosphonium cation in $\mathrm{P}\left(\mathrm{NH}_{2}\right)_{4} 1$. Distances [pm] and angles [ $\left.{ }^{\circ}\right]: \mathrm{P}-\mathrm{N} 160.7(2), \mathrm{N}-\mathrm{H} 74.9(26), \mathrm{N}-\mathrm{P}-\mathrm{N} 124.2(2)$ and $102.7(1)$, H-N-H 114(3), P-N-H 120(2).

ed from the four P-N bonds according to O'Keeffe et al.. ${ }^{[7]}$ is indicative of significant polar bonding or multiple bonds between the phosphorus and nitrogen atoms. The electrostatic repulsion between the nitrogen atoms in $\mathrm{PN}_{4}^{7-}\left(\mathrm{P}-\mathrm{N}: 171 \mathrm{pm}^{[2]}\right)$ is obviously compensated by the interaction between the nitrogen atoms and the terminal protons of the tetraaminophosphonium ion. This results in a marked shortening of the $\mathrm{P}-\mathrm{N}$ bonds by approximately $10 \mathrm{pm}$. In accord with these short $\mathrm{P}-\mathrm{N}$ bond lengths the $\mathrm{H}-\mathrm{N}-\mathrm{H}$ and $\mathrm{H}-\mathrm{N}-\mathrm{P}$ bond angles $\left(114(3)^{\circ}\right.$ and $120(2)^{\circ}$, respectively) in the tetraaminophosphonium ion indicate a significant $\mathrm{P}-\mathrm{N}$ double-bond character. Even though there are no $\mathrm{N}-\mathrm{H} \cdots \mathrm{N}$ hydrogen bonds present between the cations, the $\mathrm{NH}_{2}$ groups are fixed with regard to rotation around the $\mathrm{P}-\mathrm{N}$ bonds. Accordingly, it was possible to locate the positions of the hydrogen atoms unambiguously ${ }^{[8]}$ during $\mathrm{X}$-ray structure analysis by difference-Fourier synthesis.

\section{Experimental Procedure}

$\mathrm{SP}\left(\mathrm{NH}_{2}\right)_{3}(4.53 \mathrm{~g}, 0.04 \mathrm{~mol})$ was treated with $\mathrm{CH}_{3} \mathrm{I}(8.17 \mathrm{~g}, 0.06 \mathrm{~mol})$ in dry acetonitrile $(25 \mathrm{~mL}$ ) for 6 days at room temperature. The resulting solid $\mathbf{B}$ (yield: $76 \%$ ) was separated and washed with diethyl ether. ${ }^{31} \mathrm{P}$ NMR $\left(36.9 \mathrm{MHz}, \mathrm{CDCl}_{3}, 25^{\circ} \mathrm{C}\right)$ : $\delta=48.1(\mathrm{~s}) . \mathrm{B}(4.82 \mathrm{~g}, 0.02 \mathrm{~mol})$ was suspended in $100 \mathrm{~mL}$ of dichloromethane and treated at room temperature (duration: $3 \mathrm{~h}$ ) with a vigorous stream of $\mathrm{NH}_{3}(\mathrm{KOH}$ drying column). The resulting solid $\mathbf{C}$ was separated off and washed with diethyl ether (yield: $96 \%$ ). For purification and crystal growth, $1.0 \mathrm{~g}$ of $\mathrm{C}$ in $25 \mathrm{~mL}$ acetonitrile was transferred to a Schlenk tube, and a temperature gradient (bottom: $70^{\circ} \mathrm{C}$. top: $25^{\circ} \mathrm{C}$ ) was applied to the supernatant. Coarse-crystalline, colorless $\mathrm{C}$ deposited at the cooler end. According to X-ray powder diffraction studies and ${ }^{31} \mathrm{P}$ NMR MAS measurements the product was obtained as a single phase. IR(KBr) $\tilde{v}\left[\mathrm{~cm}^{-1}\right]=3378(\mathrm{NH}), 3280(\mathrm{NH}), 3097(\mathrm{NH}), 1078(\mathrm{PN}), 946(\mathrm{PN}) . T=180^{\circ} \mathrm{C}$ $\left(10^{-3} \mathrm{mbar}\right.$, decomposition). All reactions were carried out in dry solvents under an inert argon atmosphere.

Received: November 9, 1993 [Z 64751E German version: Angew. Chem. 1994, 106, $81 \varepsilon$

[1] W. Schnick, Angew. Chem. 1993, 105, 846; Angew: Chem. Int. Ed. Engl. 1993, 32 806.

[2] W. Schnick, J. Lücke, J. Solid State Chem. 1990, 87, 101.

[3] M. Becke-Goehring, K. Niedenzu, Chem. Ber. 1957, 90. 2072. 
[4] A. Schmidpeter, C. Weingand, Angex: Chem. 1968, 80, 234; Angen: Chem. Int. Ed. Engl. 1968, 7, 210.

[5] W. Schnick, Z. Naturforsch. B 1989, 44, 942.

[6] X-ray structure analysis of C: $\mathrm{H}_{8} \mathrm{PN}_{4} \mathrm{I}, M=221.9 \mathrm{~g} \mathrm{~mol}^{-1}$, space group $P 4 / \mathrm{nbm}, Z=2 . a=842.6(2), c=486.7(2) \mathrm{pm}, V=345.5 \times 10^{6} \mathrm{pm}^{3}, \rho_{\text {calcd }}=$ $2.133 \mathrm{~g} \mathrm{~cm}^{-3}, F(000)=208, i=71.073 \mathrm{pm}, T=173 \mathrm{~K}, \mu\left(\mathrm{Mo}_{\mathrm{Ks}}\right)=4.76 \mathrm{~mm}^{-1}$. Siemens P4 diffractometer, crystal dimensions $(\mathrm{mm}): 0.24 \times 0.20 \times 0.20 .2 \theta-\theta$ scan, $4.0 \leq 20 \leq 60.0^{\circ}, 1260$ observed reflections. 282 symmetry-independent reflections $\left(R_{\mathrm{in} 1}=0.007\right)$, structure solution with direct methods, $\mathrm{H}$-atoms by difference-Fourier synthesis, structure refinement with full matrix by the leastsquares method (16 parameters), all atoms anisotropic, $\mathrm{H}$-atoms isotropic. $R=0.022, w R=0.013$. Further details of the crystal structure investigation may be obtained from the Fachinformationszentrum Karlsruhe, D-76344 Eggenstein-Leopoldshafen (FRG), on quoting the depository number CSD400461 and the journal citation.

[7] N. E. Brese. M. O'Keeffe, Acta Crystallogr. Sect. B 1991, 47, 192.

[8] The X-ray structure analysis gave a N-H bond length of $74.9(26) \mathrm{pm}$. 